\title{
Printed Internal Pentaband WWAN Antenna Using Chip-Inductor-Loaded Shorting Strip for Mobile Phone Application
}

\author{
Yong-Ling Ban, ${ }^{1}$ Shun Yang, ${ }^{1}$ Joshua Le-Wei Li, ${ }^{1}$ and Rui Li \\ ${ }^{1}$ Institute of Electromagnetics, University of Electronic Science and Technology of China, 2006 Xi-Yuan Avenue, \\ Western High-Tech District, Sichuan, Chengdu 611731, China \\ ${ }^{2}$ College of Software Engineering, Chengdu University of Information Technology, Chengdu 610225, China
}

Correspondence should be addressed to Yong-Ling Ban, byl@uestc.edu.cn

Received 10 July 2012; Accepted 17 September 2012

Academic Editor: Minh-Chau Huynh

Copyright () 2012 Yong-Ling Ban et al. This is an open access article distributed under the Creative Commons Attribution License, which permits unrestricted use, distribution, and reproduction in any medium, provided the original work is properly cited.

\begin{abstract}
A compact size on-board printed antenna using capacitive coupled-fed excitation to generate multiple resonant modes for pentaband WWAN operation (GSM850/900/GSM1800/1900/UMTS2100) is presented in this paper. The proposed antenna occupies only a small footprint of $15 \times 25 \mathrm{~mm}^{2}$ on one corner of the circuit board and a protruded ground of $10 \times 15 \mathrm{~mm}^{2}$ is displaced with close proximity to the antenna portion. The proposed antenna has a very simple structure which is composed of two separate strips: a loop strip with an inserted chip inductor and an L-shaped feeding strip. The loop strip is shorted to the ground and generates a resonant mode at $890 \mathrm{MHz}$ to cover the GSM850/900 band ( $824-960 \mathrm{MHz}$ ) while the feeding strip contributes to the GSM1800/1900/UMTS210 band (1710-2170 MHz) operation. With such a small size, the proposed antenna can achieve compact integration on the circuit board of the mobile phone, thus the proposed scheme is quite suitable for the slim mobile phone application. Good agreements between simulations and measurements are obtained. Details of proposed antenna are presented and some key parameters are studied.
\end{abstract}

\section{Introduction}

Mobile phone antennas with compact size, low profile, and wide operation band characteristics have attracted great attention both in academic and industrial field. In recent years, a variety of small size and broadband antennas excited by the capacitive coupled-fed scheme to achieve multiband operation have been reported [1-4]. These reported antennas can be configured to occupy a compact volume inside the mobile phone for multiband operation. However, most of the reported designs did not consider the integration of internal antenna with the system ground plane because an isolation distance is often needed to guarantee the performance of wideband operation. As a result, these antennas often occupy the whole edge of the system circuit ground plane which is not so suitable for the practical application $[1,2]$. This phenomenon is also common in some traditional threedimensional antenna designs [3]. It limits the integration of the internal antenna with the associated electronic components. Recently, several novel designs with protruded ground are proposed $[5,6]$ which integrate the antenna with the system board well; furthermore, it has been shown that protruded ground can effectively suppress the surface current distribution on the ground plane away from the edge where the antenna is mounted [7]. Thus decreased near field emission can be achieved if the antenna is placed at the bottom of the mobile handset. But most of them are three-dimensioned or have a large area occupation $[5,6]$. To miniature the antenna size, chip inductors are widely used to reduce the length of the strip for a special frequency so as to realize compact designs [8-10]. A penta-band solution with protruded ground plane is reported in [11], which is promising to be implemented in the slim mobile phone designs. In this paper, we presented a WWAN internal antenna suitable to be disposed at a small corner on the circuit board to achieve compact integration. The proposed antenna has a size of $15 \times 25 \mathrm{~mm}^{2}$ which only requires a small 


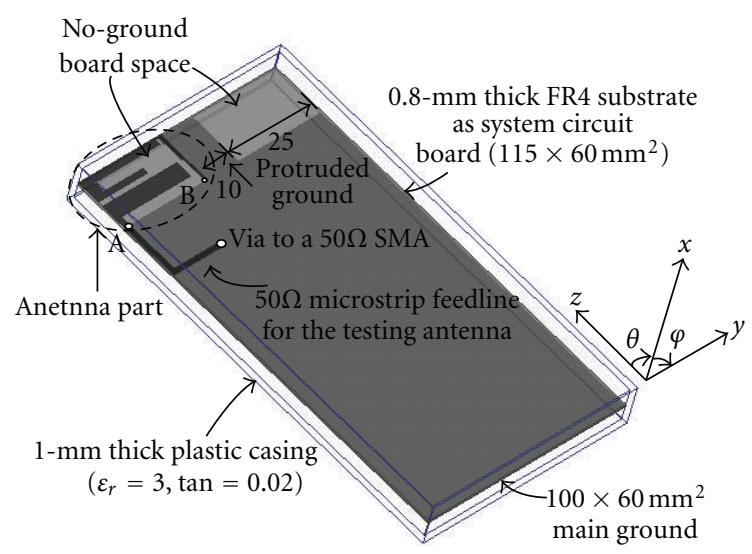

(a)

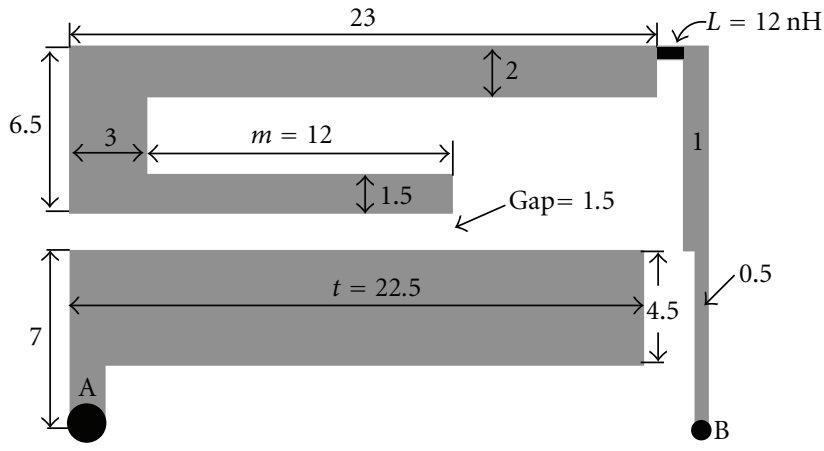

(b)

Figure 1: (a) Overall structure of the proposed antenna. (b) Dimensions of the proposed antenna (unit: $\mathrm{mm}$ ).

foot print of the system circuit plane. A protruded ground area of $10 \times 15 \mathrm{~mm}^{2}$ is left at the center part of the edge to accommodate associated electronic component such as a universal serial bus (USB) connector, and another no-ground portion at the other side of the circuit board edge near the protruded ground is promising for a another internal antenna deposition. Detailed configurable illustrations and radiation characteristics of the proposed antenna are given in the following sections.

\section{Proposed Antenna Configuration}

Figure 1(a) shows the geometry of the on-board printed coupled-fed compact antenna. The proposed antenna is printed on a small no-ground board portion of $15 \times 25 \mathrm{~mm}^{2}$ and it only occupies a small part of the edge on the mobile phone system circuit board. A $0.8 \mathrm{~mm}$ thick FR4 substrate of relative permittivity 4.4 , loss tangent 0.024 , length $115 \mathrm{~mm}$, and width $60 \mathrm{~mm}$ is used in this study. $1 \mathrm{~mm}$ thick plastic casing of relative permittivity 3.0 and loss tangent 0.02 encloses the whole substrate to simulate the mobile phone casing. As it shows in the figure, a protruded ground portion is placed closely to the antenna and connected to the main ground. The protruded ground has a size of $10 \times 15 \mathrm{~mm}^{2}$ and it is just suitable to accommodate a USB connector. Also note that on the other side of the protruded ground there is another no-ground board space of size $15 \times 25 \mathrm{~mm}^{2}$ which can be used to accommodate other internal antenna or electronic components. Furthermore, such a small and symmetrical scheme is promising to develop a compact MIMO (multiple input multiple output) antenna designs [12-14]. Figure 1(b) shows prototype of the proposed antenna which is mainly composed of two parts: an $L$-shaped feeding strip and a loop shorting strip. The $L$-shaped feeding strip is directly fed from point $A$ which is further connected to a $50-\Omega$ transmission line as shown in the Figure 1(a). The loop shorting strip is coupled-fed by the $L$-shaped feeding strip and shorted to the ground plane through a via-hole at point $\mathrm{B}$. A chip inductor

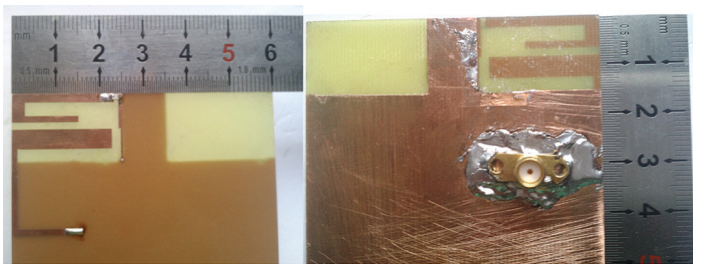

FIGURE 2: The photos of the proposed antenna.

of $L=8.2 \mathrm{nH}$ is inserted at the corner of the loop strip to shorten the path for GSM850/900 band operation. The total length of loop strip is about $60 \mathrm{~mm}$, that is, much shorter than a quarter of the wavelength for $850 \mathrm{MHz}$ which is about $90 \mathrm{~mm}$. As the lower band is mainly generated by the loop shorting strip, the front portion of the loop strip is set to be a variable of $m$ as shown in Figure 1(b). The length of the $L$ shape monopole is also set as a variable $t$ to tune the upper band operation. Detailed effects of the parameters on the antenna performance will be shown in the following sections.

\section{Result and Discussion}

Figure 2 shows the fabricated antenna with rulers to demonstrate the antenna size. The simulation is done using the high frequency simulation software (HFSS) version 12 and the measurement in conducted by Agilent N5247A vector network analyzer. Good match between measured and simulated reflection coefficient of the proposed antenna design is shown in Figure 3. The impedance matching for frequencies over the two operating bands is better than 6- $\mathrm{dB}$ return loss, which is widely used as the design specification for the internal WWAN mobile phone antennas. According to this criterion, both the simulation and the measured results cover the operation bands (GSM850/900 GSM1800/1900/UMTS2100) perfectly. The simulated input impedance of the proposed antenna on the smith chart is shown in Figure 4 to provide more impedance information. 


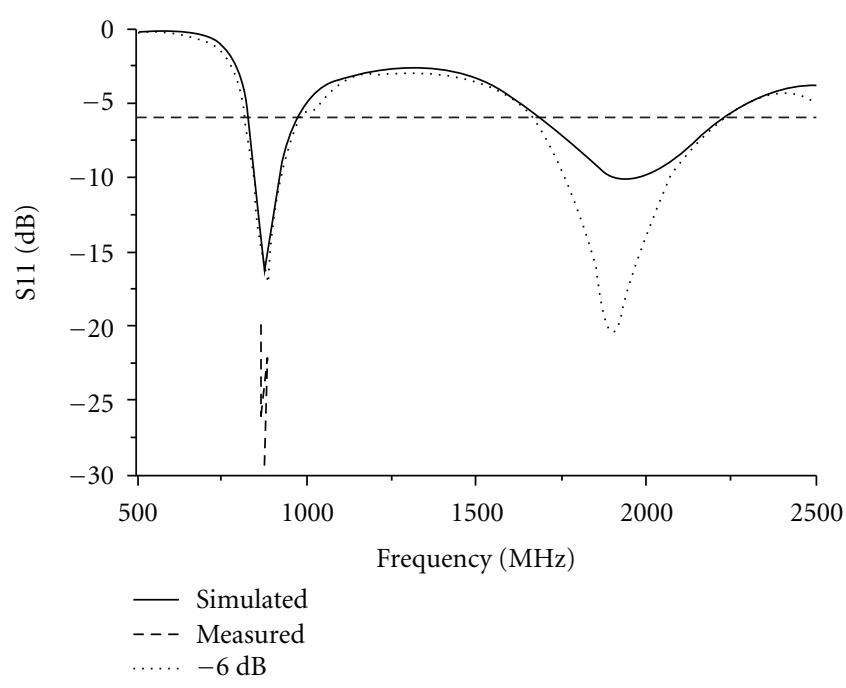

FIgURE 3: Measured and simulated S11 for the proposed antenna.

A dashed-line circle is drawn in the smith chart to demonstrate the region in which the impedance is well matched.

In order to classify the function of different parts of proposed antenna, the operating principles are analyzed. Figure 5 shows simulation reflection coefficient of the comparison between the proposed antenna and reference antennas. The corresponding Ref1 antenna has only the feed strip while the Ref2 case has no inserted inductor. For the Ref1 case, there is no resonance near $900 \mathrm{MHz}$ and the resonance of the upper band is also some kind of weak due to absence of the bended monopole. And for the Ref2 case, it is seen that both the lower band and the upper band are shifted towards higher frequencies and this phenomenon is especially obvious in the lower band. These results support the idea that the higher band is generated by the $L$-shaped feeding strip and also slightly affected by the loop strip while the lower band operation is dominantly decided by the loop strip. It also indicates that the inductor can effectively reduce the length of strip for specific resonance which helps to realize the miniature of the antenna design.

Simulated current distributions on the antenna part and ground plane at $890 \mathrm{MHz}$ and $1940 \mathrm{MHz}$ are shown in Figure 6. The directional arrows show the current flowing with varied colors. Corresponding magnitude of different color is shown as label on the left. At the frequency of $890 \mathrm{MHz}$, the current flows along the loop strip and the magnitude of the current are smallest at the front part while it increases to the largest value at the shorting point. At the same time, the current on the ground plane is well aligned in the same direction which also contributes to the lower band radiation. While at the frequency of $1940 \mathrm{MHz}$, there is strong current distribution on the feeding strip which shows that the feeding strip is the main radiator at $1940 \mathrm{MHz}$ for the antenna.

Simulated reflection coefficient and current distributions for the case with and without USB mounted on the protruded ground are presented in Figures 7 and 8 to explore the possibility of integrating a USB for the practical

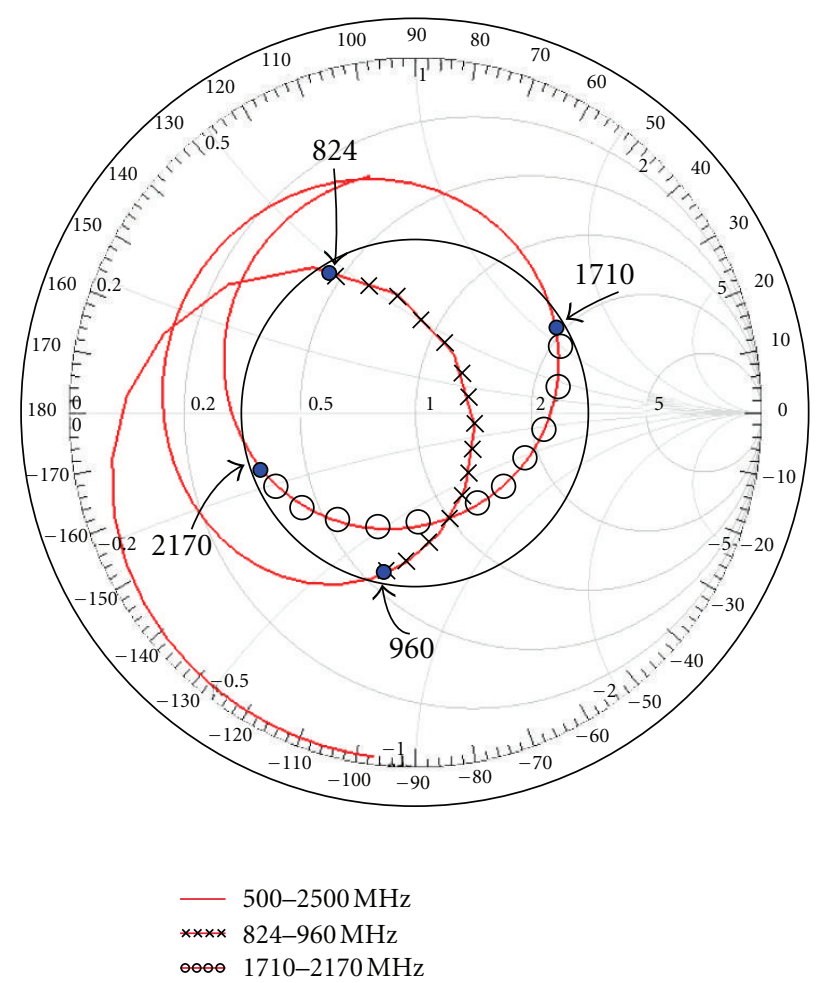

FIgURE 4: Simulated input impedance on the Smith chart.

applications. To simulate the influence of the USB connector on the antenna performance a cubic conductor with a size of $9 * 8 * 4 \mathrm{~mm}^{3}$ is placed under the protruded ground. The simulated reflection coefficient demonstrates a slight frequency shifting at the upper band but still covers the upper operation band from $1710 \mathrm{MHz}$ to $2170 \mathrm{MHz}$; meanwhile there is almost no change to the reflection coefficient in the lower band. The simulated frequency range is set to be from 500 to $3000 \mathrm{MHz}$ on purpose to show the change more clearly. As it can be observed from the reflection coefficient result in Figure 7, there is another resonant mode around $2700 \mathrm{MHz}$; this resonant mode is generated by the strip between grounding point $\mathrm{B}$ and the inserted inductor $L$ as the high frequency current is blocked by the inductor. As the protruded ground is placed closely to the strip which generates the $2700 \mathrm{MHz}$ resonant mode, a USB connector affects the $2700 \mathrm{MHz}$ resonant mode while causing small variance in other bands. This analysis can be further verified in the current distribution at the higher band in Figure 8 . It is observed from the simulated current distribution with and without the presence of USB connector, there is a very little change of the current distribution on the antenna and surrounding area. The high frequency current along the loop strip is effectively confined between the grounding point B and the inserted inductor $L$.

A parametric study of the major parameters on tuning the antenna's lower and upper bands is conducted. Figure 9(a) shows the simulated reflection coefficient of the proposed antenna when the value of the inserted inductor is selected to be $3.9 \mathrm{nH}, 8.2 \mathrm{nH}$, and $15 \mathrm{nH}$ which are available in the lab. In Figure 9(a), it is found that the excited resonant 


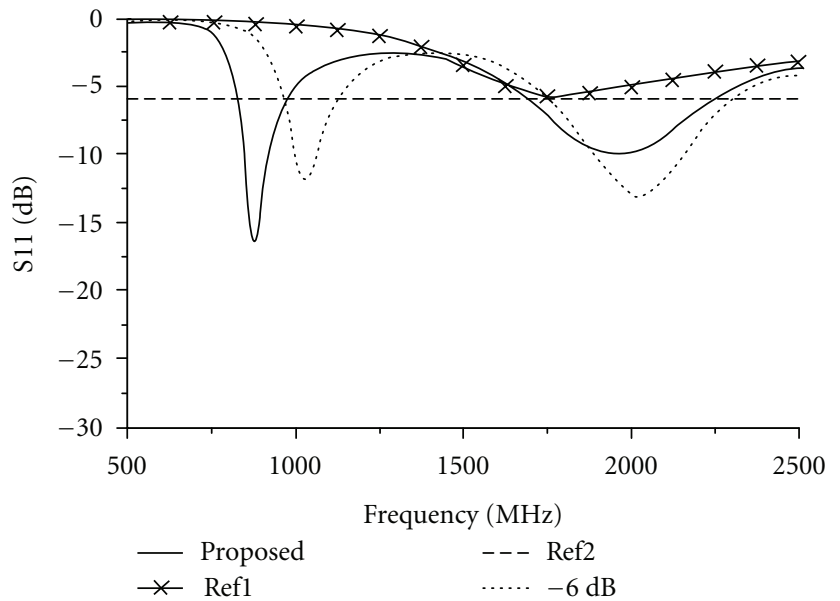

FIGURE 5: Comparison of the proposed antenna with two reference antennas.

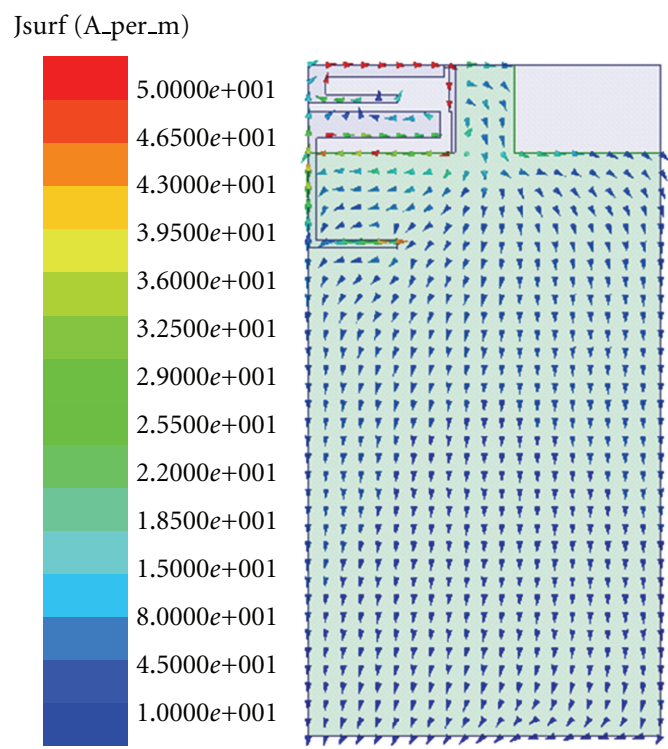

(a)

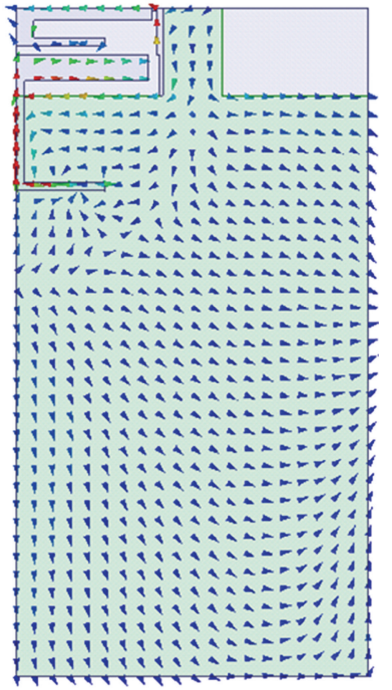

(b)

FIgURE 6: Current distribution at frequency of (a) $890 \mathrm{MHz}$ and (b) $1940 \mathrm{MHz}$.

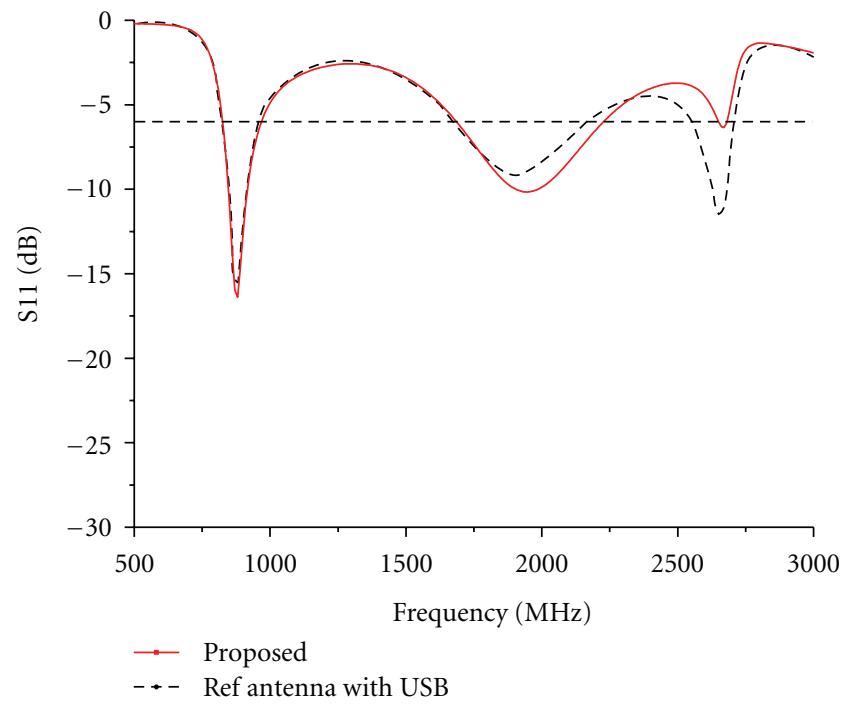

FIGURE 7: Comparison of reflection coefficient between the antenna with and without USB connector. 


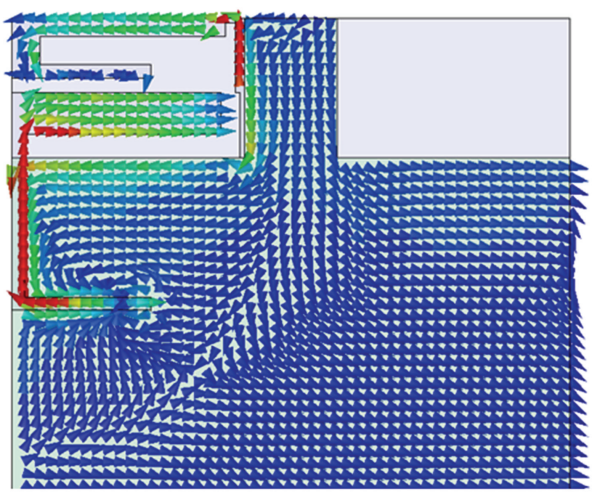

(a)

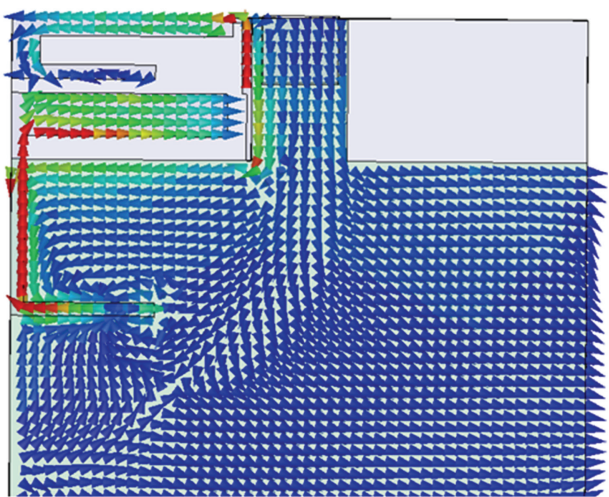

(b)

FIGURE 8: Simulated current distribution with (a) and without (b) the presence of USB.

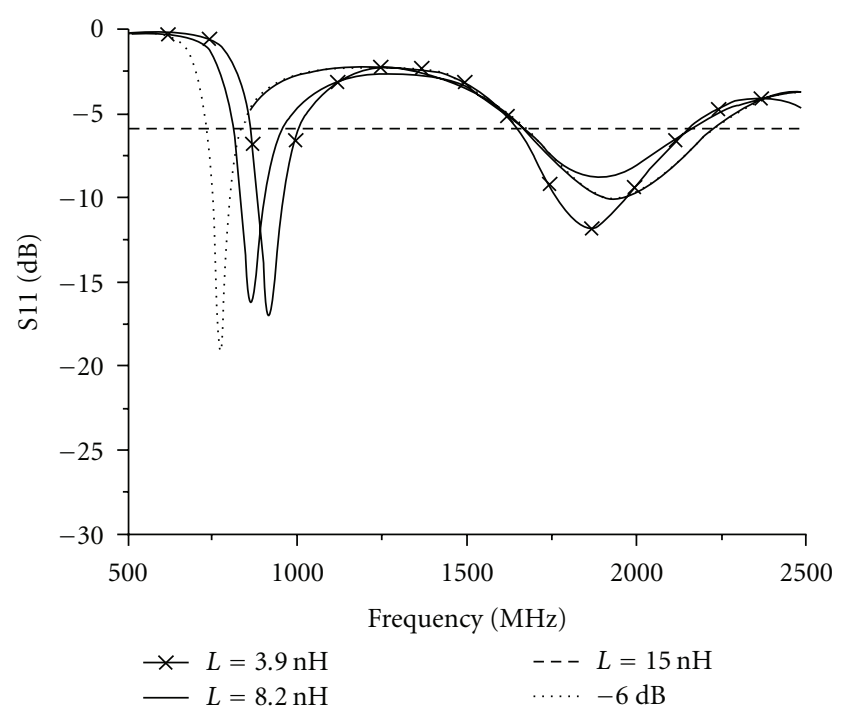

(a)
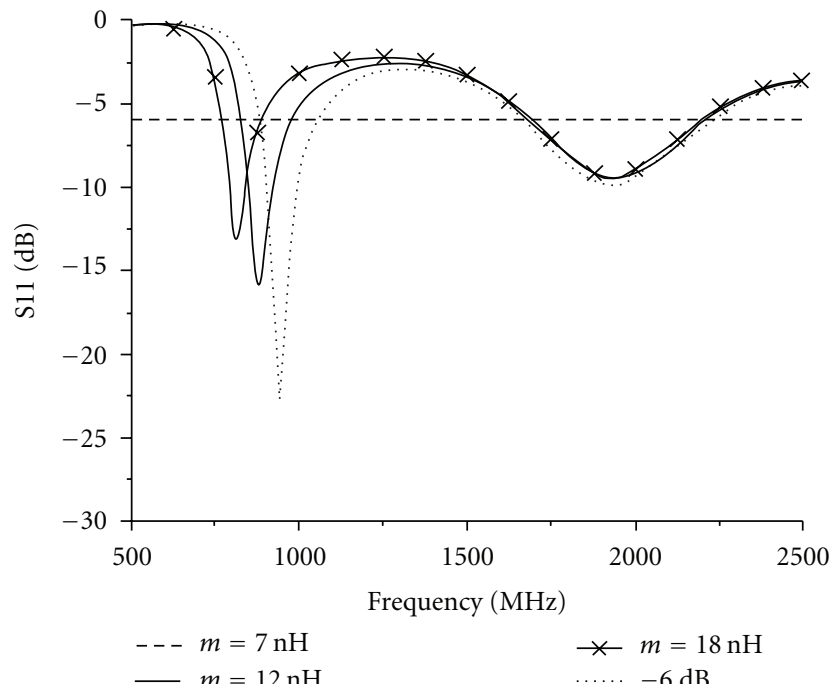

(b)

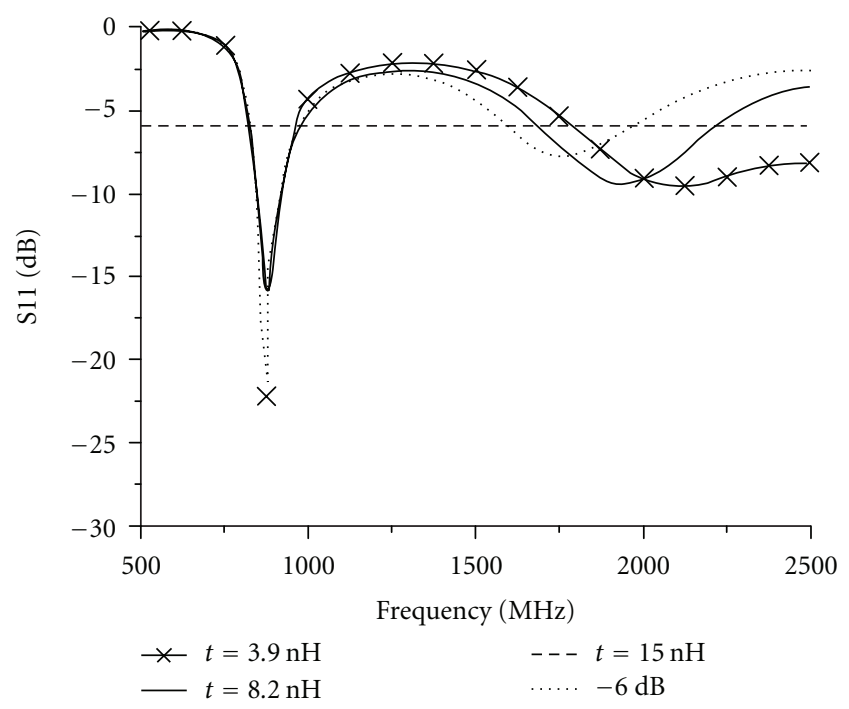

(c)

FIGURE 9: Simulated reflection coefficient for the proposed antenna as a function of (a) the value of the inserted inductor, (b) the length of the coupling strip and (c) the length of the feeding strip. Other dimensions are the same as in Figure 1. 


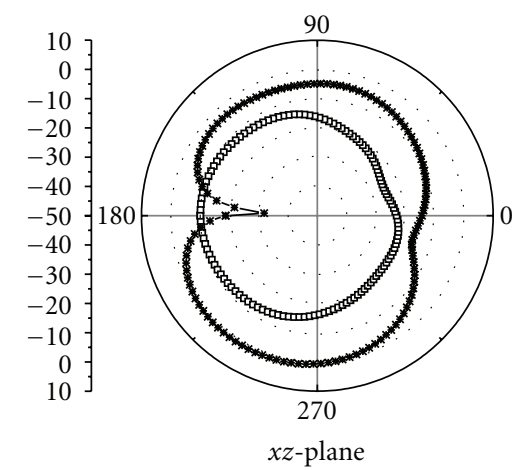

(a)

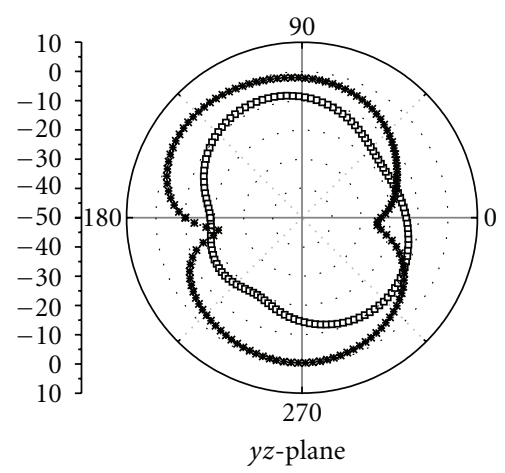

(b)

FIgURE 10: Measured radiation pattern of the proposed antenna at the frequencies of $890 \mathrm{MHz}$ and $1940 \mathrm{MHz}$ (line with rectangle: E-phi; line with cross: E-theta).

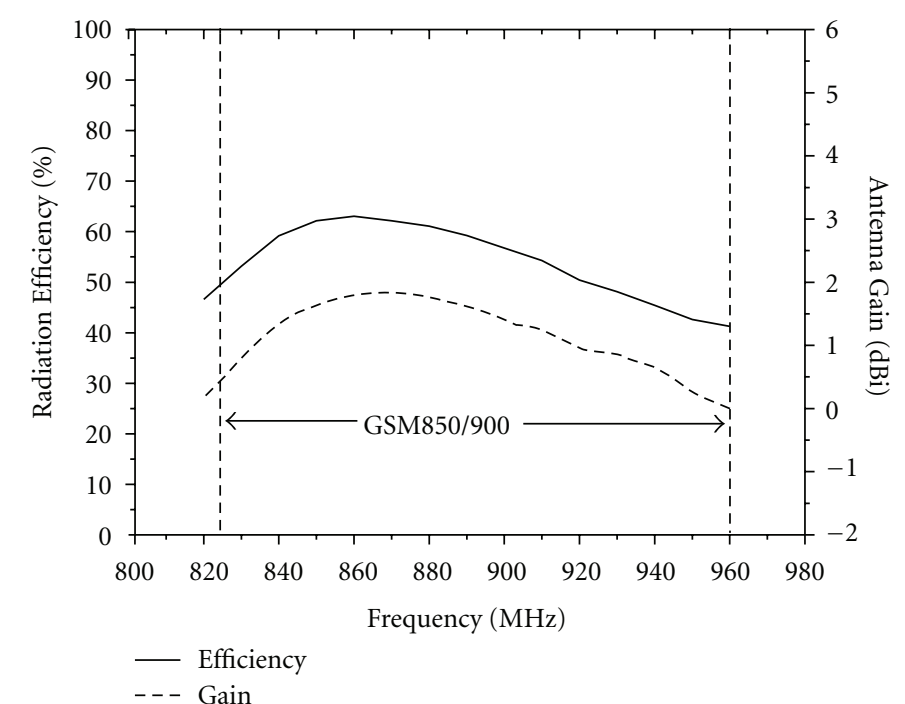

(a)

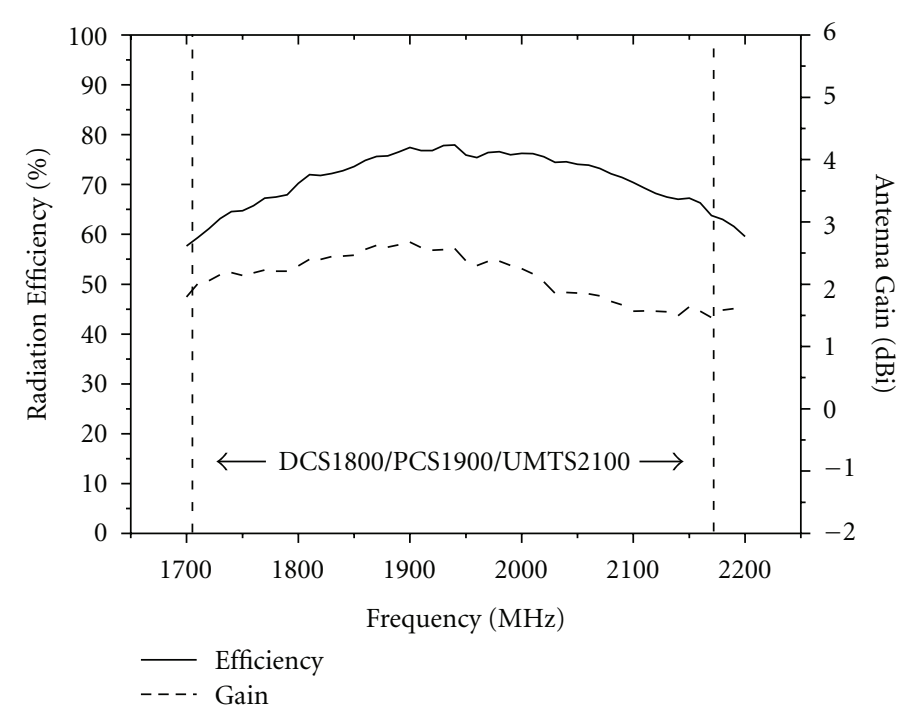

(b)

FIGURE 11: Measured antenna radiation efficiency and antenna gain for the proposed antenna at (a) lower band and (b) upper band. 
mode is shifted to the lower frequencies in the lower band when the value of the inductor $L$ is increased. Meanwhile, only small variations are found in the upper band which verifies that the inserted inductor mainly affects the lower band and is effective to reduce strip length for a special resonant mode. Effects of the length of the front portion of the loop strip are studied in Figure 9(b), where simulated reflection coefficient of the proposed antenna is presented when the strip length $m$ varied from $7 \mathrm{~mm}$ to $18 \mathrm{~mm}$. There is great similarity between Figures 9(a) and 9(b) that along the change of $m$ there is significant effect on the lower band while subtle effect on the upper band. This is reasonable as the loop is the main radiator of the lower band operation in this scheme. From Figures 9(a) and 9(b), it can be concluded that the inserted inductor and the loop strip jointly determine the resonant mode of the lower band. On the other hand, there is significant change on the upper band and little variation is found in the lower band when the length of the feeding strip is increased from $19.5 \mathrm{~mm}$ to $23.5 \mathrm{~mm}$ as shown in Figure 9(c). This is also reasonable because the feeding strip controls the upper band resonant mode.

The radiation characteristics of the proposed antenna are also studied. Figure 10 shows the two-dimensional radiation pattern of the presented antenna at the frequencies of $890 \mathrm{MHz}$ and $1940 \mathrm{MHz}$. For each frequency, it is observed from three different planes, namely, $x z$-plane, $y z$-plane, and $x y$-plane. Dipole-like radiation pattern is found at $890 \mathrm{MHz}$ which means a dumbbell-like shape radiation pattern at the $E$-plane and a circle one in the $H$-plane. However, when it comes to the upper band, the radiation characteristic varies more quickly in different directions due to surface current of the ground plane. As it is shown in Figure 6, the current distribution on the ground is quite uniform and contributes to the radiation of the $900 \mathrm{MHz}$. But at the frequency of $1900 \mathrm{MHz}$, the length of the system ground plane is comparable to the resonant wavelength, so there are current nulls excited on the system ground plane, which results in nulls and dips in the obtained radiation patterns radiation. Figure 11 shows the measured antenna radiation efficiency and antenna gain. The efficiency ranges from $42 \%$ to $63 \%$ over the GSM850/900 band and the efficiency varies from $57 \%$ to $75 \%$ for the GSM1800/1900/UMTS2100 band. The efficiency over the five operation bands is all above $40 \%$, which is acceptable for the practical mobile antenna application. The measured gain is about 0 to $1.2 \mathrm{dBi}$ and $1.6-2.5 \mathrm{dBi}$ over the lower and upper bands, respectively. Good radiation characteristics are generally obtained for the proposed antenna.

\section{Conclusion}

In this paper, a compact penta-band antenna design for mobile phone application is presented. With the presence of the chip inductor, the resonant strip length for the GSM850/900 band operation is significantly reduced. Due to its small size and simple structure it is promising to be implemented in the slim smart mobile phone designs by using PCB fabrication techniques with low cost. Moreover, Good impedance match and radiation characteristics are found in the five operation bands, making it preponderant for application in the small-size mobile phone for WWAN/LTE operating communication.

\section{References}

[1] C. T. Lee and K. L. Wong, "Uniplanar coupled-fed printed PIFA for WWAN/WLAN operation in the mobile phone," Microwave and Optical Technology Letters, vol. 51, no. 5, pp. 1250-1257, 2009.

[2] K. L. Wong, M. F. Tu, T. Y. Wu, and W. Y. Li, "Small-size coupled-fed printed pifa for internal eight-band lte/gsm/umts mobile phone antenna," Microwave and Optical Technology Letters, vol. 52, no. 9, pp. 2123-2128, 2010.

[3] Y. L. Ban, C. Q. Lei, J. H. Chen, S. C. Sun, Z. X. Xie, and F. Ye, "Compact coupled-fed PIFA employing T-shaped monopole with two stubs for eight-band LTE/WWAN internal mobile phone," Journal of Electromagnetic Waves and Applications, vol. 26, pp. 973-985, 2012.

[4] W. Y. Chen and K. L. Wong, "Wideband coupled-fed PIFA for HAC penta-band clamshell mobile phone," Microwave and Optical Technology Letters, vol. 51, no. 10, pp. 2369-2374, 2009.

[5] S. C. Chen and K. L. Wong, "Low-profile, small-size, wireless wide area network handset antenna close integration with surrounding ground plane," Microwave and Optical Technology Letters, vol. 54, pp. 623-629, 2012.

[6] F. H. Chu and K. L. Wong, "Internal coupled-fed loop antenna integrated with notched ground plane for wireless wide area network operation in the mobile handset," Microwave and Optical Technology Letters, vol. 54, pp. 599-605, 2012.

[7] S. C. Chen and K. L. Wong, "Hearing aid-compatible internal LTE/WWAN bar-type mobile phone antenna," Microwave and Optical Technology Letters, vol. 53, no. 4, pp. 774-781, 2011.

[8] K. L. Wong and S. C. Chen, "Printed single-strip monopole using a chip inductor for penta-band WWAN operation in the mobile phone," IEEE Transactions on Antennas and Propagation, vol. 58, no. 3, pp. 1011-1014, 2010.

[9] Y. L. Ban, J. H. Chen, J. L. W. Li, and Y. J. Wu, "Printed ultrawideband antenna for LTE/GSM/UMTS wireless USB dongle applications," IEEE Antennas and Wireless Propagation Letters, vol. 11, pp. 403-406, 2012.

[10] K. L. Wong and C. T. Lee, "Small-size wideband monopole antenna closely coupled with a chip-inductor-loaded shorted strip for 11-band WWAN/WLAN/WiMAX operation in the slim mobile phone," Microwave and Optical Technology Letters, vol. 53, no. 2, pp. 361-366, 2011.

[11] Y. W. Chi and K. L. Wong, "Internal compact dual-band printed loop antenna for mobile phone application," IEEE Transactions on Antennas and Propagation, vol. 55, no. 5, pp. 1457-1462, 2007.

[12] J. Zhang, J. Ou Yang, K. Z. Zhang, and F. Yang, "A novel dual-band MIMO antenna with lower correlation coefficient," International Journal of Antennas and Propagation, vol. 2012, Article ID 512975, 7 pages, 2012.

[13] C. Yang, Y. Yao, J. S. Yu, and X. D. Chen, "Novel compact multiband MIMO antenna for mobile terminal," International Journal of Antennas and Propagation, vol. 2012, Article ID 691681, 9 pages, 2012.

[14] Q. H. Zeng, Y. Yao, S. H. Liu, J.S. Yu, P. Xie, and X. D. Chen, "Tetraband small-size printed strip MIMO antenna for mobile handset application," International Journal of Antennas and Propagation, vol. 2012, Article ID 320582, 8 pages, 2012. 

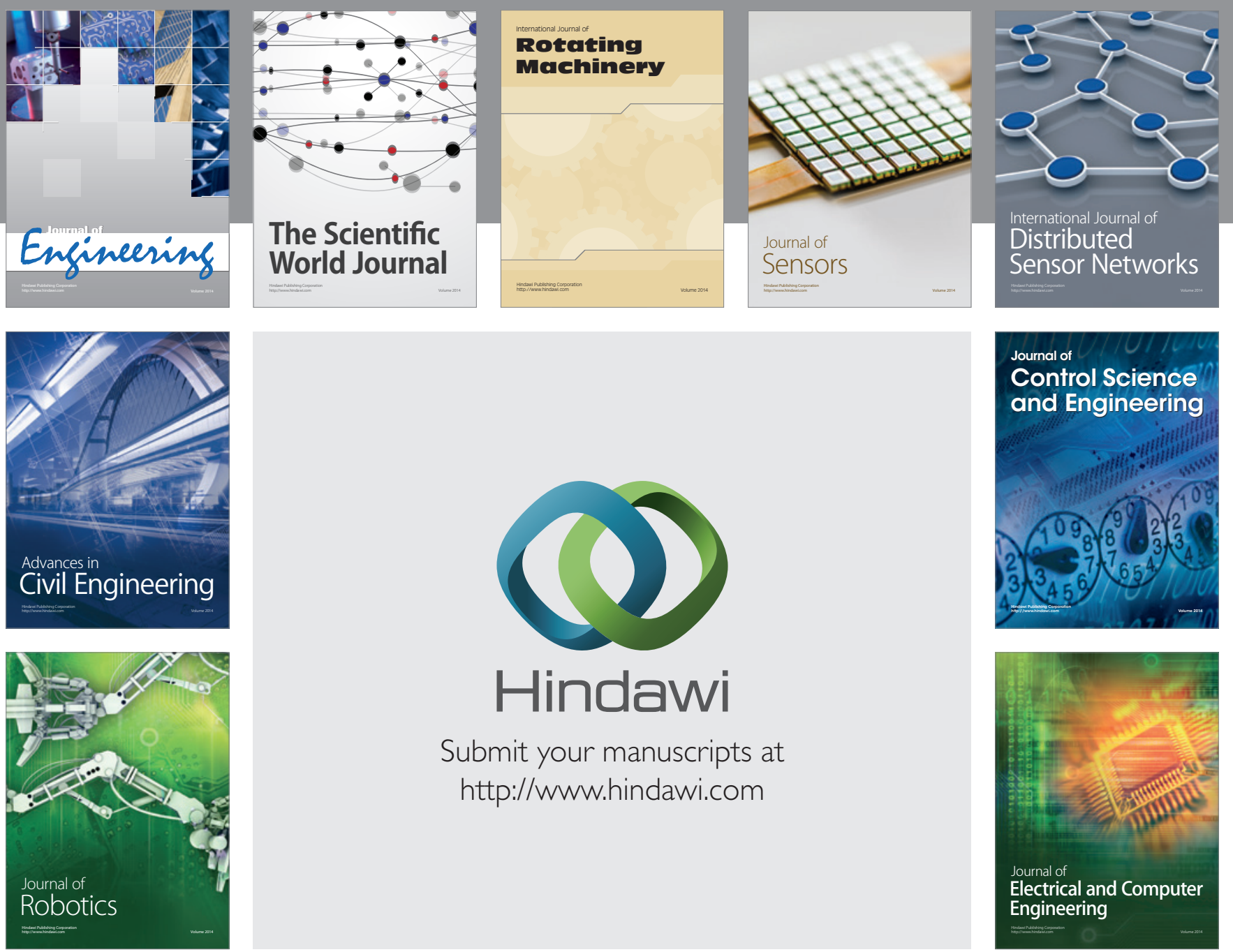

Submit your manuscripts at

http://www.hindawi.com
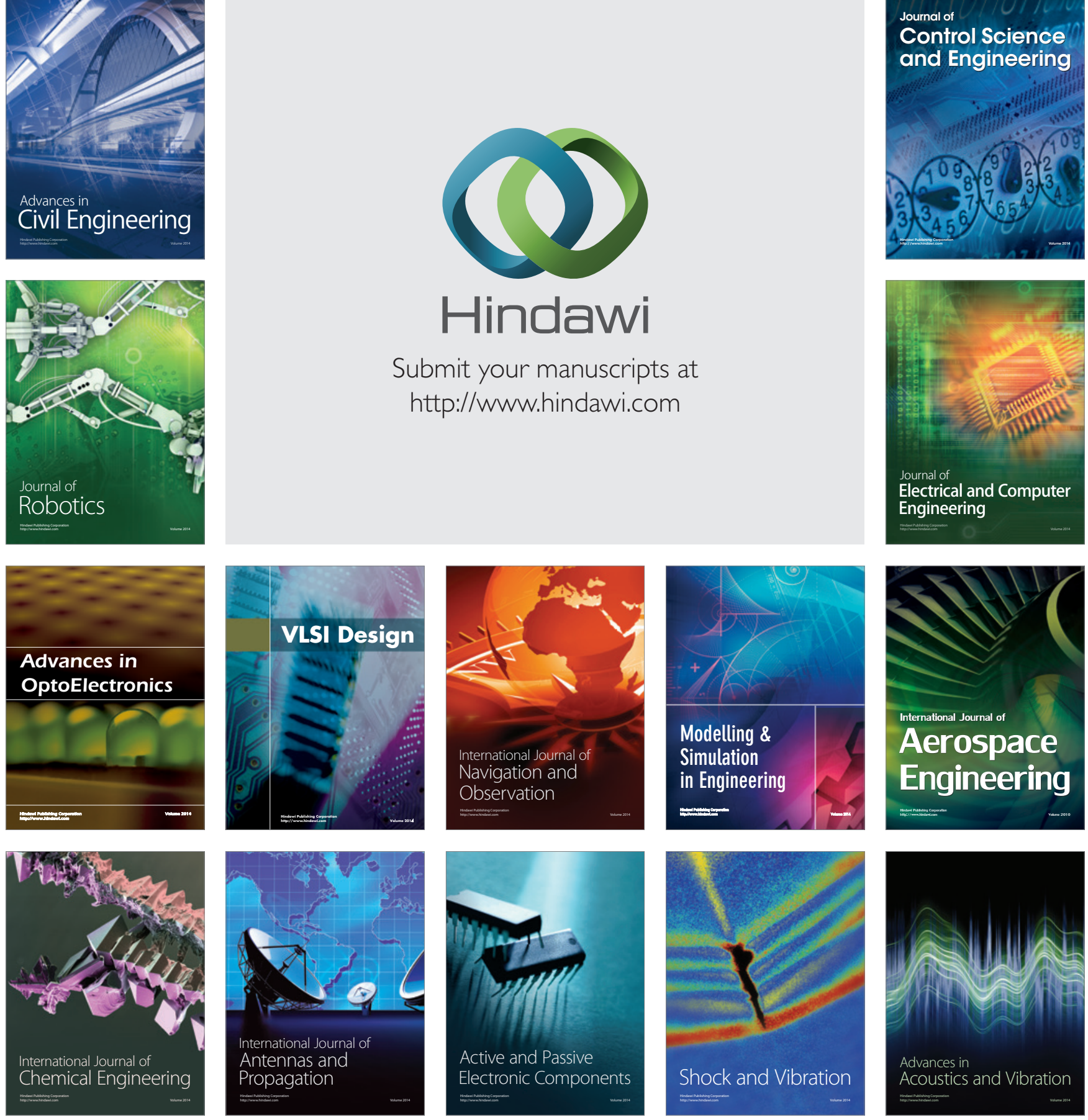